\title{
Espermatozoides caprinos criopreservados em meio à base de leite desnatado acrescido deglutationa reduzida
}

\author{
Goat spermatozoa after freezing in skimmed-milk extender supplemented with reduced glutathione
}

\author{
Adriana Trindade Soares ${ }^{\mathrm{I}, \mathrm{II}}$ Sildivane Valcácia Silva ${ }^{\mathrm{I}}$ Felipe Costa Almeida \\ Paula Fernanda Barbosa de Araújo Lemos ${ }^{\text {II }}$ José Ferreira Nunes $^{\text {III }}$ Christina Alves Peixoto ${ }^{\text {IV }}$ \\ Maria Madalena Pessoa Guerra ${ }^{*}$
}

RESUMO

\begin{abstract}
Visando avaliar o efeito da adição de glutationa reduzida (GSH) ao diluente de congelação de sêmen caprino à base de leite desnatado, utilizou-se sêmen de cinco reprodutores Boer. Após colheita e avaliação, procedeu-se à formação do pool dos ejaculados e diluição em leite desnatado e glicerol $7 \%$, acrescido de antioxidantes: G1) Controle; G2) GSH $2 m M m L^{-1}$; G3) GSH $5 m M m L^{-1}$ e G4)

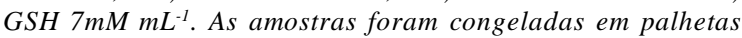
$(0,25 \mathrm{~mL})$ e armazenadas a $-196^{\circ} \mathrm{C}$. Após descongelação, avaliou-se a integridade de membrana plasmática (iMP) $e$ acrossomal (iAc), potencial de membrana mitocondrial $(P M M)$, cinética e ultraestrutura. Os grupos Controle e GSH $\left(2,5\right.$ e $\left.7 \mathrm{mM} \mathrm{mL}^{-1}\right)$ não diferiram $(P>0,05)$ em iMP, iAc, PMM e cinética. Na análise ultraestrutural, os porcentuais de membrana plasmática (cabeça e cauda) e acrossoma íntegros não diferiram $(P>0,05)$ entre grupos. Todavia, o grupo Controle apresentou maior porcentual $(P<0,05)$ de gametas com axonema íntegros do que os de GSH (2, 5 e $\left.7 \mathrm{mM} \mathrm{mL}^{-1}\right)$. Maior porcentagem $(P<0,05)$ de espermatozoides com mitocôndrias íntegras foi observada no grupo Controle do que nos de GSH (5 e $\left.7 \mathrm{mM} \mathrm{mL}^{-1}\right)$. Conclui-se que a adição de GSH (2, 5 e $7 \mathrm{mM} \mathrm{mL}^{-1}$ ) em diluente de congelação de sêmen caprino, à base de leite desnatado, não preserva a integridade dos espermatozoides.
\end{abstract}

Palavras-chave: antioxidantes, sêmen, viabilidade espermática.

\section{ABSTRACT}

Aiming to evaluate in vitro effect of different concentrations of glutathione reduced (GSH) in skimmedmilk and glycerol 7\% it was used semen from five Boer bucks. After collect and evaluation, a pool of samples was diluted in skimmed-milk and glycerol 7\% plus antioxidant: G1) Control;

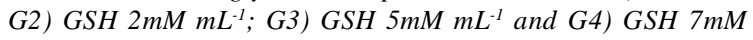
$m L^{-1}$. Samples were frozen in straws $(0.25 \mathrm{~mL})$ and stored at $196^{\circ} \mathrm{C}$. After thawing, samples were subjected to integrity of the plasma membrane (iMP) and acrosomal (iAc), mitochondrial membrane potential (MMP), kinematic and ultrastructure analysis. Control and GSH (2,5 and $\left.7 \mathrm{mM} \mathrm{mL}^{-1}\right)$ groups did no differ $(P>0.05)$ in iMP, iAc, PMM and kinematic parameters. In the ultrastructural analysis, percentages of acrosome and plasma membrane (tail and head region) intact did not differ $(P>0.05)$ between groups. However, Control group had higher percentage $(P<0.05)$ of gametes with intact axonemes than those of $G S H\left(2,5\right.$ and $\left.7 \mathrm{mM} \mathrm{mL}^{-1}\right)$ groups. Higher percentage $(P<0.05)$ of sperms with intact mitochondrias were observed on Control group than those of GSH (5 and $7 \mathrm{mM} \mathrm{mL}^{-1}$ ). It can be concluded that the GSH (2, 5 and $7 \mathrm{mM} \mathrm{mL}^{-1}$ ) addition in skimmed-milk diluent to freeze goat semen did not preserve sperm integrity.

Key words: antioxidants, semen, sperm viability.

\section{INTRODUÇÃO}

A redução da fertilidade, associada à inseminação artificial com sêmen congelado, é atribuída à ocorrência de danos espermáticos durante a congelação e descongelação, causando alterações ultraestruturais, bioquímicas e funcionais que reduzem a viabilidade espermática. Estudos têm relatado que muitos mecanismos de defesa antioxidante estão envolvidos nos sistemas biológicos e que o equilíbrio

'Laboratório de Andrologia, Departamento de Medicina Veterinária, Universidade Federal Rural de Pernambuco (UFRPE), 52171-900, Recife, PE, Brasil. E-mail: mpguerra@dmv.ufrpe.br. Autor para correspondência.

"Empresa Estadual de Pesquisa Agropecuária da Paraíba (EMEPA), João Pessoa, PB, Brasil.

IIILaboratório de Tecnologia do Sêmen, Universidade Estadual do Ceará (UECE). Fortaleza, CE, Brasil.

${ }^{\mathrm{IV}}$ Centro de Tecnologias Estratégicas do Nordeste (CETENE), Recife, PE, Brasil. 
entre os benefícios e danos de ROS e antioxidantes, in vivo e in vitro, é necessário para o funcionamento reprodutivo normal. Dessa forma, durante as manipulações espermáticas em laboratório, especialmente na ausência do plasma seminal, os antioxidantes celulares são importantes em preservar a motilidade e a habilidade dos espermatozoides de sofrerem capacitação e reação do acrossoma (GUERRA et al., 2004).

O processo de criopreservação estabelece significante redução da glutationa no sêmen de diversas espécies (GADEA et al., 2004, GADEA et al., 2008). Porém, o efeito deletério deste processo pode ser minimizado, em parte, pela adição de GSH exógena, pois as células utilizam GSH do sistema thioredox para reverter o estresse oxiadativo (GADEA et al., 2005b). Nesse sentido, tem-se adicionado GSH ao diluente de congelação ou descongelação do sêmen de pequenos ruminantes (SINHA et al., 1996; GARDÓN et al., 2003), bovino (GADEA et al., 2008), suíno (GADEA et al., $2005 a, 2005 b$ ). Ainda pouco se sabe sobre o metabolismo da GSH no sêmen, e ainda permanecem algumas questões a serem esclarecidas a respeito de sua qualidade espermática e sua capacidade fecundante pós-descongelação (GADEA, et al., 2005b).

O presente trabalho objetivou avaliar in vitro o efeito da adição de GSH ao diluente de congelação de sêmen caprino, à base de leite desnatado e glicerol $7 \%$ por meio da avaliação da cinética espermática, integridade da membrana plasmática, integridade de acrossoma, atividade mitocondrial e análise ultraestrutural.

\section{MATERIAL E MÉTODOS}

Foram utilizados cinco reprodutores caprinos da raça Boer, idade variando de 24 a 36 meses. Os animais foram submetidos a regime intensivo, alimentados com $400 \mathrm{~g} \mathrm{dia}^{-1}$ de concentrado comercial, além de capim elefante (Pennisetum purpureum), sal mineral e água ad libitum. As colheitas de sêmen foram realizadas com vagina artificial. Foram obtidos seis ejaculados por reprodutor, obedecendo à frequência de três colheitas de sêmen por semana, correspondendo a 30 amostras de sêmen.

Após colheita, o sêmen foi submetido à avaliação, selecionando-se aqueles com motilidade $\geq 70,0 \%$ e vigor $\geq 3$. Em seguida, formou-se o pool de ejaculados, o qual foi centrifugado duas vezes $(2500 \mathrm{~g}$; 10 minutos) em tampão Tris, na proporção de 1:9 (v:v; sêmen:solução de lavagem). A seguir, o pool foi diluído em meio à base de leite desnatado e glicerol (7\%), na concentração de $240 \times 10^{6}$ espermatozoides $\mathrm{mL}^{-1}$, acrescido de antioxidantes: G1) Controle (sem antioxidante); G2) GSH $2 \mathrm{mM} \mathrm{mL}^{-1}$; G3) GSH $5 \mathrm{mM} \mathrm{mL}^{-1}$; e G4) GSH 7 $\mathrm{mM} \mathrm{mL}^{-1}$. Após diluição, as amostras foram acondicionadas em palhetas $(0,25 \mathrm{~mL})$ e submetidas à refrigeração e congelação em sistema automatizado (modelo TK $3000^{\circledR}$ - TK Tecnologia em Congelação LTDA, Uberaba, Brasil) e, na curva de congelação rápida, após atingir a temperatura de $-120^{\circ} \mathrm{C}$, as palhetas foram armazenadas em nitrogênio líquido $\left(-196^{\circ} \mathrm{C}\right)$.

Após descongelação $\left(37^{\circ} \mathrm{C}\right.$, por 30 segundos), alíquotas de sêmen de cada grupo foram submetidas às análises de cinética em sistema computadorizado (CASA; Sperm Class Analyzer, Microptics, S.L. Version 3.2.0 Barcelona, Spain), estrutura em microscópio de epifluorescência (Carl Zeiss, Göttingen, Germany) e ultraestrutura espermática em microscópio eletrônico de transmissão (FEI Company, Eindhoven, Netherland). Para análise da cinética espermática, utilizou-se $10 \mu \mathrm{L}$ da amostra de sêmen em câmara de $\operatorname{Makler}^{\circledR}\left(37^{\circ} \mathrm{C}\right)$, examinada em microscópio de contraste de fase (100x) acoplado ao sistema CASA, no qual se observaram os parâmetros de motilidade total (MT, \%), motilidade progressiva (MP, \%), velocidade curvilínea (VCL, $\mu \mathrm{m} \mathrm{s}^{-1}$ ), velocidade progressiva (VSL, $\mu \mathrm{m} \mathrm{s}^{-1}$ ), velocidade de trajeto (VAP, $\mu \mathrm{m} \mathrm{s}^{-1}$ ), linearidade (LIN, \%), retilinearidade (STR, \%), oscilação (WOB, \%), amplitude de deslocamento da cabeça (ALH, $\mu \mathrm{m}$ ), frequência do batimento de flagelo (BCF, $\mathrm{Hz}$ ), segundo VERSTEGEN et al. (2002).

Para análise da estrutura por sondas fluorescentes, avaliou-se a integridade da membrana plasmática pelo método de coloração dupla com Diacetato de Carboxifluoresceína (DCF) e Iodeto de Propídio (IP), segundo COLETO et al. (2002). Um total de 200 espermatozoides foi avaliado em aumento de 400x, usando filtro de emissão DBP 580-630nm e excitação DBP 485/20nm, e classificados como membrana intacta quando corados em verde ou membrana danificada quando corados em vermelho. Para análise de integridade do acrossoma, usou-se isocianato de fluoresceína conjugado a Peanut agglutinin (FITC-PNA; ROTH et al., 1998). Foram avaliados 200 espermatozoides por lâmina, com aumento de 1000x, sob óleo de imersão, usando filtro de emissão LP 515nm e BP 450-490nm para excitação. Os gametas foram classificados como portadores de acrossomas intactos, quando apresentaram a região acrossomal corada com fluorescência verde, ou acrossoma reagido, quando apresentavam uma faixa verde fluorescente na região equatorial da cabeça espermática ou não apresentavam fluorescência verde em toda a cabeça. Para análise de potencial da 
membrana mitocondrial (PMM), utilizou-se fluorocromo catiônico lipofílico JC-1 (GUTHRIE \& WELCH, 2006). Um total de 200 espermatozoides foi avaliado com aumento de 1000x sob óleo de imersão usando filtro de emissão LP 515nm e BP 450-490nm para excitação. As células coradas em laranja foram classificadas com alto PMM, enquanto aquelas coradas em verde foram classificadas com baixo PMM.

Para análise da ultraestrutura espermática, foram usadas amostras de sêmen in natura e congeladas/descongeladas, as quais foram centrifugadas três vezes ( $800 \mathrm{~g} ; 5$ minutos) em solução tampão (PBS) e fixadas overnight em solução de Glutaraldeído, Paraformaldeído e tampão Cacodilato de Sódio, seguindo protocolo de SARAIVA et al. (2009).

As análises estatísticas foram realizadas utilizando-se o procedimento PROC GLM do programa SAS (2001). Os dados das variáveis estudadas foram submetidos à análise de variância, obedecendo a um delineamento inteiramente casualizado, utilizando-se o teste F para comparação dos quadrados médios dos fatores testados e as médias foram comparadas pelo teste Tukey a $5 \%$ de probabilidade.

\section{RESULTADOS E DISCUSSÃO}

Os parâmetros da cinética espermática não diferiram $(\mathrm{P}>0,05)$ entre os grupos estudados. Obtevese média $\_$desvio padrão, respectivamente, para os grupos Controle e GSH 2, 5 e 7Mm de 77,22+18,56, $84,98 \pm 10,16,73,11 \pm 21,32$ e $64,13 \pm 20,36$ de MT;
$26,26 \pm 12,21,27,46 \pm 8,06,19,00 \pm 10,33$ e $21,15 \pm 10,32 \mathrm{de}$ MP; 47,28+6,30; 48,53+6,32; 42,86+6,55 e 48,40+5,73 deLIN; 74,00+1,46, 73,76+4,42, 64,61+17,65 e 74,78+1,13 deSTR; 63,70 $\pm 8,11,65,75 \pm 6,95,60,01 \pm 6,95$ e $64,61 \pm 7,59$ de WOB; 35,98 $\pm 5,83,37,06 \pm 7,55,31,76 \pm 6,45$ e $34,70 \pm 5,45$ de VSLe 48,50+7,66, 50,25+9,90, 42,73+11,09 e 46,40 \pm 7,32 de VAP.

Os resultados de MT e MP evidenciam que, ao se aumentar a concentração de GSH, reduzem-se os porcentuais de gametas vivos e com MP, ratificando o resultado da análise de integridade da membrana plasmática, realizada por sonda fluorescente (Tabela 1). Os parâmetros de MP, LIN, STR, WOB, VSL, VAPe alto PMM (Tabela 1) mostram que a adição de GSH 5 $\mathrm{mM} \mathrm{mL} \mathrm{m}^{-1}$ determinou valores menores do que com $2 \mathrm{e}$ $7 \mathrm{mM} \mathrm{mL}^{-1}$, mostrando relação entre PMM e cinética espermática. O baixo porcentual de espermatozoides com MP pode ser atribuído à congelação, que causa danos subletais e reduzem a qualidade do movimento espermático (PESCH \& BERGMANN, 2006), possivelmente devido à exposição espermática ao $\mathrm{O}_{2}$, resultando em aumento da produção de ROS. Este fato evidencia que a adição de GSH, nas concentrações usadas, não foi adequada para inativar ROS como $\mathrm{O}_{2}^{-}$e $\mathrm{OH}^{-}$.

A porcentagem de espermatozoides com membranas plasmática e acrossomal íntegras, assim como com alto PMM (Tabela 1), não diferiu entre os grupos Controle e tratados com GSH $\left(2,5\right.$ e $\left.7 \mathrm{mM} \mathrm{mL}^{-1}\right)$. No entanto, constatou-se maior porcentual de gametas com membrana plasmática íntegra nas amostras do

Tabela 1 - Resultados (média \pm desvio padrão) das análises por fluorescência (iMP, iAc e aPMM) e microscopia eletrônica de transmissão (MET) (iMCa, iAc, iMC, AX e MIT) de espermatozoides obtidos de reprodutores caprinos da raça Bôer, in natura e criopreservados em diluente à base de leite desnatado e glicerol 7\% acrescido de Glutationa reduzida (GSH) em diferentes concentrações.

\begin{tabular}{|c|c|c|c|c|c|}
\hline \multirow{2}{*}{ Parâmetros Espermáticos } & \multirow{2}{*}{ Sêmen in natura } & \multicolumn{4}{|c|}{ 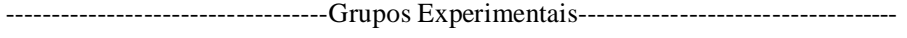 } \\
\hline & & Controle & $\mathrm{GSH} 2 \mathrm{mM} \mathrm{mL}^{-1}$ & GSH $5 \mathrm{mM} \mathrm{mL}^{-1}$ & $\mathrm{GSH} 7 \mathrm{mM} \mathrm{mL}^{-1}$ \\
\hline \multicolumn{6}{|c|}{--1-10 } \\
\hline $\operatorname{iMP}(\%)$ & - & $39,55 \pm 8,91$ & $43,31 \pm 9,91$ & $39,14 \pm 9,80$ & $36,09 \pm 7,66$ \\
\hline iAc (\%) & - & $38,76 \pm 12,23$ & $35,05 \pm 11,90$ & $38,08 \pm 12,95$ & $46,21 \pm 10,71$ \\
\hline $\operatorname{aPMM}(\%)$ & - & $47,45 \pm 9,30$ & $47,51 \pm 9,04$ & $38,41 \pm 9,48$ & $40,21 \pm 3,61$ \\
\hline & --------Análi & Microscopia E & hica de Transmissã & & \\
\hline $\mathrm{iMCa}(\%)$ & $39,63 \pm 5,34^{\mathrm{a}}$ & $28,28 \pm 4,52^{\mathrm{b}}$ & $35,25 \pm 5,34^{\mathrm{b}}$ & $26,51 \pm 2,50^{\mathrm{b}}$ & $26,13 \pm 3,38^{\mathrm{b}}$ \\
\hline iAc $(\%)$ & $65,33 \pm 11,18^{\mathrm{a}}$ & $33,66 \pm 5,27^{b}$ & $27,40 \pm 3,20^{\mathrm{b}}$ & $30,11 \pm 1,64^{\mathrm{b}}$ & $31,38 \pm 2,35^{\mathrm{b}}$ \\
\hline $\operatorname{iMC}(\%)$ & $64,35 \pm 7,76^{\mathrm{a}}$ & $36,31 \pm 4,38^{\mathrm{b}}$ & $30,75 \pm 2,52^{\mathrm{b}}$ & $30,31 \pm 2,98^{\mathrm{b}}$ & $29,58 \pm 2,56^{\mathrm{b}}$ \\
\hline $\mathrm{AX}(\%)$ & $80,33 \pm 4,33^{\mathrm{a}}$ & $55,66 \pm 7,00^{\mathrm{b}}$ & $43,90 \pm 5,94^{\mathrm{c}}$ & $44,18 \pm 5,79^{\mathrm{c}}$ & $33,96 \pm 4,34^{\mathrm{d}}$ \\
\hline $\operatorname{MIT}(\%)$ & $72,82 \pm 11,33^{\mathrm{a}}$ & $61,53 \pm 5,81^{\text {ab }}$ & $50,86 \pm 3,94^{\mathrm{b}}$ & $30,58 \pm 1,49^{\mathrm{c}}$ & $28,43 \pm 2,19^{c}$ \\
\hline
\end{tabular}

iMP: membrana plasmática íntegra; iAc: acrossoma íntegro; aPMM: alto potencial de membrana mitocondrial; iMCa: membrana plasmática íntegra na região da cabeça do espermatozoide; iMC: membrana plasmática íntegra na região da cauda do espermatozoide; AX: axonema íntegro; MIT: mitocôndrias íntegras. Letras diferentes na mesma linha indicam diferença estatística $(\mathrm{P}<0,05)$. 
GSH $2 \mathrm{mM} \mathrm{mL}^{-1}$, corroborando as ressalvas de BILODEAU et al. (2001), enfatizando que, maiores concentração de GSH determinam porcentuais menores de gametas com membrana plasmática intacta, provavelmente devido ao fato de concentrações elevadas de GSH causarem danos aos espermatozoides bovinos, por alterar a osmolaridade celular, fragilizar a membrana plasmática e causar ruptura nessa estrutura. Apesar do porcentual de gametas com acrossoma íntegro não haver diferido entre grupos, verificou-se que concentrações mais elevadas deste antioxidante foram benéficas à integridade desta estrutura celular. Sabe-se que a GSH remove o $\mathrm{H}_{2} \mathrm{O}_{2}$, inibidor da tirosina fosfatase (enzima envolvida na fosforilação da tirosina) (HECHT \& ZICK, 1992), impedindo o início da capacitação dos espermatozoides, conforme evidenciado por GADEA et al. (2005b) quando GSH 1 e 5mM foi adicionada ao meio de desconcongelação de sêmen suíno refletindo, em baixa porcentagem de espermatozoides capacitados, comparado ao grupo controle. Dessa forma, esperava-se melhor resultado ao utilizar GSH $7 \mathrm{mM} \mathrm{mL}^{-1}$. Todavia, a análise da membrana plasmática mostrou o inverso, deixando dúvida quanto à melhor concentração de GSH a ser usada em diluidor de congelação de sêmen caprino, uma vez que os dois parâmetros se referem à integridade de membranas que participam do processo de capacitação espermática. Além disso, esses resultados contradizem os relatos de SINHA et al. (1996), que, ao congelarem espermatozoides caprinos em diluente à base de Tris, glicerol e GSH (2 e 5mM), observaram maior motilidade, integridade de acrossoma e taxas de concepção ao usarem $5 \mathrm{mM}$ de $\mathrm{GSH}$, sugerindo proteção às membranas espermáticas da peroxidação lipídica.

Neste estudo, observou-se que 2,5 e $7 \mathrm{mM}$ $\mathrm{mL}^{-1}$ de glutationa não preservou o PMM dos espermatozoides congelados. Todavia, na concentração de $2 \mathrm{mM} \mathrm{mL}^{-1}$ obteve-se porcentual maior do que em 5 e $7 \mathrm{mM} \mathrm{mL}^{-1}$. O porcentual médio obtido no grupo Controle $(47,45 \pm 9,30 \%)$ foi semelhante aos $40,33 \%$ relatados por BATISTA et al. (2009), em espermatozoides caprinos da raça Boer. MARCOJIMÉNEZ et al. (2006) constataram que o processo de congelação/descongelação de espermatozoides caprinos da raça Murciano-granadina determinou considerável redução do número de células com alto PMM (59,00\% in natura vs $27,70 \%$ congelado), avaliados pelo JC-1. No entanto, o porcentual de gametas com alto PMM observado por estes autores foi inferior àquele obtido neste estudo, sugerindo variação entre raças, diluente ou método de congelação.
Neste trabalho foi hipotetizado que a adição de GSH ao meio de congelação protegeria o espermatozoide durante a criopreservação. No entanto, nas concentrações utilizadas, não se observou melhora significativa na qualidade destes gametas, pós-descongelação. Esse fato pode ser atribuído à presença da caseína, antioxidante natural encontrado no leite, conforme foi ressaltado por FOOTE et al. (2002), os quais observaram que a adição dos antioxidantes glutationa, superóxido dismutase, ácido ascórbico, hipotaurina, tempo e tempol ao diluente à base de leite e glicerol não preservaram a motilidade e a fertilidade do sêmen bovino. Entretanto, KHALIFA \& SAIDY (2006) evidenciaram significativo efeito da adição de vários antioxidantes (EDTA, catalase bovina, GSH, piruvato de sadio) em meio de diluição de sêmen quimicamente definido sobre a motilidade progressiva de espermatozóides caprinos submetidos à criopreservação sem a remoção do plasma seminal por centrifugação. Isso pode ser explicado pelo fato de que, meios quimicamente definidos eliminam os efeitos adversos das secreções da glândula bulbouretral sobre a viabilidade espermática estocada em meio contento leite (SIAS et al., 2005). Além disso, a centrifugação é um método que consume tempo e causa danos às células espermáticas (VILLEMURE et al., 2003). Todavia, em virtude de diferenças na composição das membranas plasmáticas de espermatozoides caprinos e bovinos (PURDY, 2006), acreditava-se que GSH no diluente de congelação do sêmen caprino mantivesse a integridade de suas membranas.

Observa-se que a congelação do sêmen caprino não causou hiperativação das células espermáticas nas amostras dos grupos Controle e GSH $\left(2,5\right.$ e $\left.7 \mathrm{mM} \mathrm{mL}^{-1}\right)$, uma vez que não se observou VCL $>250,0 \mathrm{~mm} \mathrm{~s}^{-1}$, VSL $\leq 100,0 \mathrm{~mm}^{-1}, \mathrm{LIN} \leq 30 \%$ e ALHmax $\geq 9,0 \mathrm{~mm} \mathrm{~s}^{-1}$ (MORTIMER \& MAXWELL, 1999). No entanto, com base nos resultados das sondas fluorescentes, esperava-se que esses gametas apresentassem sinais de hiperativação, devido à ocorrência de danos na membrana plasmática causados pela congelação (CHECK \& CHECK, 1991), resultando no aumento da quantidade de espermatozoides capacitados (MAXWELL \& WATSON, 1996).

Os dados ultraestruturais (Tabela 1) da membrana plasmática (cabeça e cauda) e do acrossoma não diferiram $(\mathrm{P}>0,05)$ entre grupos, mas foram inferiores $(\mathrm{P}<0,05)$ aos do sêmen in natura (Figura $1 \mathrm{~A}$ ), que também apresentaram células com rompimento e ondulação da membrana plasmática na região da cabeça (Figura 1B). Todavia, as amostras de sêmen in natura e do grupo Controle apresentaram maior porcentual $(\mathrm{P}<0,05)$ de gametas com axonema 


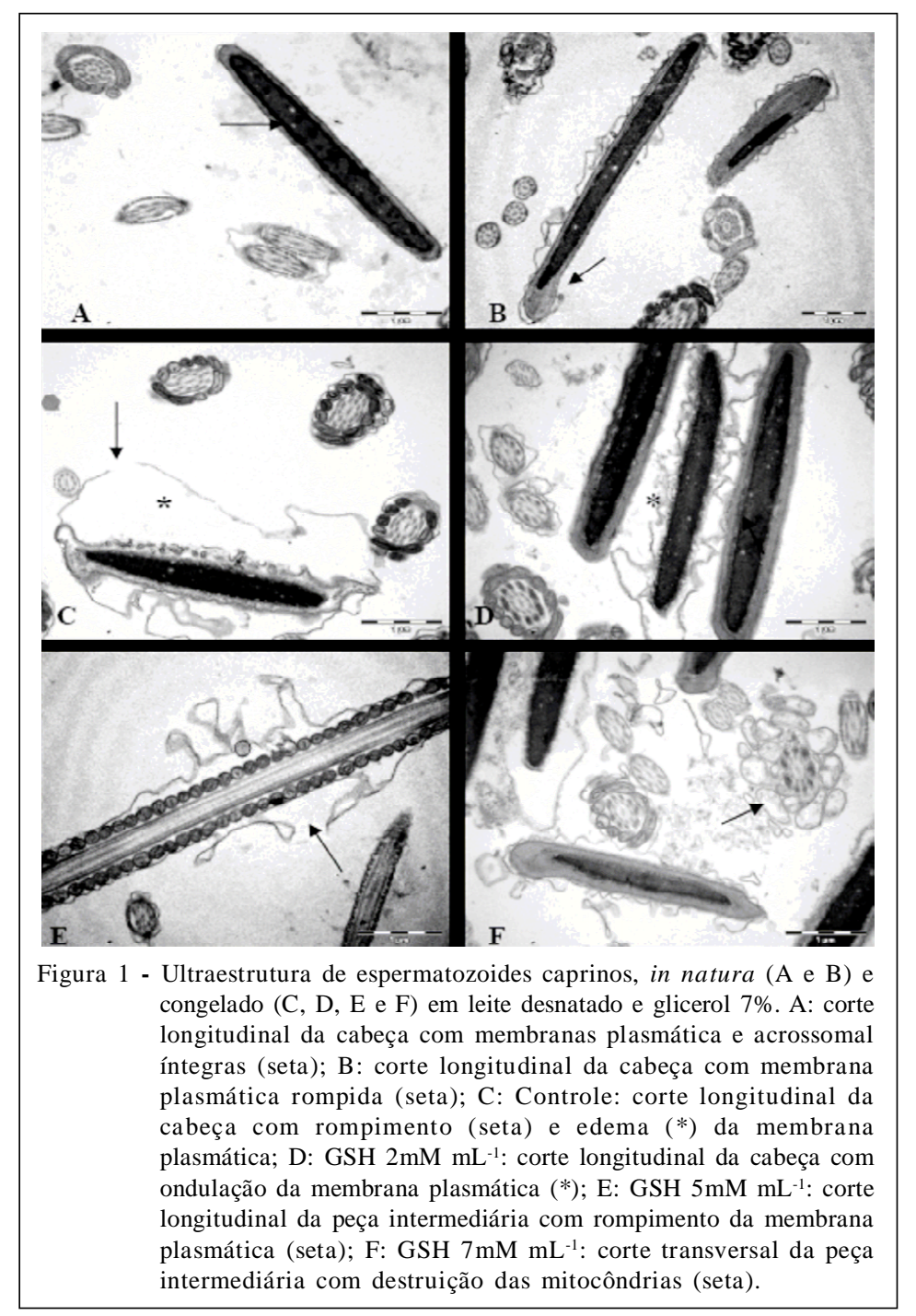

íntegros do que as dos grupos tratados com GSH (2, 5 e $\left.7 \mathrm{mM} \mathrm{mL}^{-1}\right)$. Menos $(\mathrm{P}<0,05)$ espermatozoides com axonemas intactos foi observado no GSH $7 \mathrm{mM} \mathrm{mL}^{-1}$ do que nos demais grupos. O grupo Controle apresentou maior porcentagem $(\mathrm{P}<0,05)$ de gametas com mitocôndrias íntegras do que os de GSH (5 e 7mM $\left.\mathrm{mL}^{-1}\right)$, mas não diferiram $(\mathrm{P}>0,05)$ do sêmen in natura e do GSH $2 \mathrm{mM} \mathrm{mL}^{-1}$. No sêmen congelado, observaramse células com perda de material acrossomal; edema, ondulação e rompimento da membrana plasmática na cabeça (Figuras 1C, 1D) e cauda (Figura 1E); desorganização do axonema e das mitocôndrias (Figura 1F).

Conforme o esperado, o sêmen in natura apresentou maior porcentual de gametas com membrana plasmática, acrossoma e mitocôndrias íntegras, em virtude de não ter sido submetido a nenhum estresse térmico, químico ou de manipulação. Todavia, devido ao ejaculado ser composto de várias subpopulações, com gametas de diferentes épocas de maturação (HAFEZ \& HAFEZ, 2004), justifica as alterações na estrutura dessas células in natura, porém em menor proporção do que nas congeladas (Controle e GSH).

Lesões na membrana plasmática (cabeça e cauda) foram semelhantes às descritas em espermatozoides de bodes (HASHIDA et al., 2005), apesar de os gametas possuírem tamanhos, formas e composição lipídica distintas (PURDY, 2006). As análises com sondas fluorescentes e MET mostraram resultados semelhantes, ao evidenciarem que, apesar de não diferirem estatisticamente, o porcentual de gametas com membrana plasmática íntegra na região da cabeça foi maior no grupo GSH $2 \mathrm{mM} \mathrm{mL}^{-1}$ do que no Controle. A baixa MP observada nos espermatozoides congelados de caprinos pode ser justificada pela ocorrência de danos ultraestruturais nas membranas plasmática e acrossomal (LEBOEUF et al., 2000). 
No presente trabalho, por meio das análises realizadas foi possível elucidar o comportamento da célula criopreservada em meio adicionado de glutationa reduzida em diferentes concentrações, podendo ajudar na formulação de diluidores mais eficazes quanto às suas propriedades antioxidativas. Os parâmetros avaliados podem identificar portadores de deficiência reprodutiva e direcionar a seleção de reprodutores capacitados a programas de melhoramento genético auxiliados pela reprodução assistida.

Por conseguinte, de acordo com os resultados obtidos, conclui-se que a adição de GSH $\left(2,5 \mathrm{e} 7 \mathrm{mM} \mathrm{mL}^{-1}\right)$ em diluente à base de leite desnatado e glicerol 7\% para congelação do sêmen caprino não preserva a integridade dos espermatozoides.

\section{AGRADECIMENTOS}

À Coordenação de Aperfeiçoamento de Pessoal de Nível Superior (CAPES), pela concessão de bolsa durante a realização do Doutorado; à Fundação de Amparo à Ciência e Tecnologia do Estado do Pernambuco (FACEPE); ao Conselho de Desenvolvimento Científico e Tecnológico (CNPq), pelo apoio financeiro e à Empresa Estadual de Pesquisa Agropecuária da Paraíba S. A (EMEPA/PB), pela autorização de uso dos reprodutores.

\section{REFERÊNCIAS}

BATISTA, A.M. et al. Efeito dos métodos Swim-up e Percoll sobre a viabilidade espermática de amostras criopreservadas de sêmen caprino. In: CONGRESSO BRASILEIRO DE REPRODUÇÃO ANIMAL, 18., 2009, Belo Horizonte, Brasil. Anais... Belo Horizonte: CBRA, 2009. p.409. (CD Rom).

BILODEAU, J.F. et al. Thiols prevent $\mathrm{H}_{2} \mathrm{O}_{2}$-mediated loss of sperm motility in cryopreserved bull semen. Theriogenology, v.56, p.275-286, 2001. Disponível em: <http://www.sciencedirect.com/science/article/pii/ S0093691X01005623>. Acesso em: 24 ago. 2011. doi:10.1016/S0093-691X(01)00562-3.

CHECK, M.L.; CHECK, J.H. Poor hypo-osmotic swelling test results from cryopreserved sperm despite preservation of sperm motility. Archives of Andrology, v.26, p.37-41, 1991. Disponível em: 〈http://www.ncbi.nlm.nih.gov/pubmed/2009029>. Acesso em: 24 ago. 2011. doi: 10.3109/01485019108987624.

COLETO, Z.F. et al. Avaliação do sêmen congelado de caprinos com drogas fluorescentes. Revista Brasileira de Medicina Veterinária, v.24, p.101-104, 2002.

FOOTE, R.H. et al. Motility and fertility of bull sperm in whole milk extender containing antioxidants. Animal Reproduction Science, v.71, p.13-23, 2002. Disponível em: $<\mathrm{http}: / / \mathrm{www}$.sciencedirect.com/science/article/pii/ S0378432002000180>. Acesso em: 24 ago. 2011. doi:10.1016/ S0378-4320(02)00018-0.

GADEA, J. et al. Cooling and freezing of boar spermatozoa: suplementation of the freezing media with reduced glutathione preserves sperm function. Journal of Andrology, v.26, p.396404, 2005a. Disponível em: <http://www.andrologyjournal.org/ cgi/content/abstract/26/3/396>. Acesso em: 24.ago. 2011. doi: $10.2164 /$ jandrol.04155.

GADEA, J. et al. Decrease in glutathione content in boar sperm after cyopreservation: effect of the addition of reduced glutathione to the freezing and thawing extenders. Theriogenology, v.62, p.690-701, 2004. Disponível em: <http://www.sciencedirect.com/science/article/pii/ S0093691X03004655>. Acesso em: 24 ago. 2011. doi:10.1016/j.theriogenology.2003.11.013.

GADEA, J. et al. Supplementation of the dilution medium after thawing with reduced glutathione improves function and the in vitro fertilizing ability of frozen-thawed bull spermatozoa. International Journal of Andrology, v.31, p.40-49, 2008. Disponível em: <http://onlinelibrary.wiley.com/doi/10.1111/ j.1365-2605.2007.00756.x/full>. Acesso em: 24 ago.2011. doi: $10.1111 / \mathrm{j} .1365-2605.2007 .00756 . x$.

GADEA, J. et al. Suplementation of the thawing media with reduced glutathione improves function and the in vitro fertilizing ability of boar spermatozoa after cryopreservation. Journal of Andrology, v.26, p.749-756, 2005b. Disponível em: <http://www.andrologyjournal.org/cgi/content/full>. Acesso em: 24 ago. 2011. doi: 10.2164/jandrol.05057.

GARDÓN, J.C. et al. Addition of reduced glutathione to thawing medium improved the sperm motility and reduced ROS generation in frozen ovine and caprine spermatozoa. Reproduction, Fertility and Development, v.18, p.155, 2003. Disponível em: <http://www.publish.csiro.au/ ?paper=RDv18n2Ab94>. Acesso em: 24. ago. 2011. http:// dx.doi.org/10.1071/RDv18n2Ab94.

GUERRA, M.M.P. et al. Papel de oxidantes e antioxidantes na andrologia (Revisão de literatura). Revista Brasileira de Reprodução Animal, v.28, p.187-195, 2004. Disponível em: <http://www.cbra.org.br/pages/publicacoes/rbra/download/ v28n4.pdf>. Acesso em: 26 ago. 2011.

GUTHRIE, H.D.; WELCH G.R. Determination of intracellular reactive oxygen species and high mitochondrial membrane potential in Percoll-treated viable boar sperm using fluorescence-activated flow cytometry. Journal of Animal Science, v.84, p.2089-2100, 2006. Disponível em: <http:// jas.fass.org/content/84/8/2089.full.pdf+html>. Acesso em: 24 ago. 2011. doi:10.2527/jas.2005-766.

HAFEZ, B.; HAFEZ, E.S.E. Reprodução animal. São Paulo: Manole, 2004. 513p.

HASHIDA, N.H. et al. Ultrastrutural studies of fresh, frozenthawed and acrossome-reacted goat sperm. Biomedical Research, v.16, p.119-123, 2005. Disponível em: <http:/ /www.biomedres.org/journal/pdf/125.pdf $>$. Acesso em: 24 ago. 2011.

HECHT, D.; ZICK, Y. Selective inhibition of protein tyrosine phosphatase activities by $\mathrm{H}_{2} \mathrm{O}_{2}$ and vanadate in vitro. Biochemical and Biophysical Research Communications, v.188, p.773779, 1992. Disponível em: <http://www.sciencedirect.com/science/ article/pii/0006291X92911238>. Acesso em: 24 ago. 2011. doi:10.1016/0006-291X(92)91123-8. 
KHALIFA, T.A.A.; EL-SAID, B.E. Pellet-freezing of Damascus goat semen in a chemically defined extender. Animal Reproduction Science, v.93, p.303-315, 2006. Disponível em: <http://www.sciencedirect.com/science/article/ pii/S0378432005002423 >. Acesso em: 24 ago. 2011. doi:10.1016/j.anireprosci.2005.08.008

LEBOEUF, B. et al. Production and storage of goat semen for artificial insemination. Animal Reproduction Science, v.62, p.113-141, 2000. Disponível em: <http://www.sciencedirect.com/ science/article/pii/S037843200000>. Acesso em: 24 ago. 2011. doi:10.1016/S0378-4320(00)00156-11561.

MARCO-JIMÉNEZ, F. et al. Morphometric chances in goat sperm heads induced by cryopreservation. Cryobiology, v.52, p.295-304, 2006. Disponível em: <http://www.sciencedirect.com/ science/article/pii/S0011224006000046>. Acesso em: 24 ago. 2011. doi:10.1016/j.cryobiol.2006.01.002.

MAXWELL, W.M.C.; WATSON, P.F. Recent progress in the preservation of ram semen. Animal Reproduction Science, v.42, p.55-65, 1996. Disponível em: <http://www.sciencedirect.com/ science/article/pii/0378432096015448>. Acesso em: 24 ago. 2011. doi:10.1016/0378-4320(96)01544-8.

MORTIMER, S.T.; MAXWELL, W.M.C. Kinematic definition of ram sperm hyperactivation. Reproduction, Fertility and Development, v.11, p.25-30, 1999. Disponível em: <http://www.publish.csiro.au/nid/44/paper/ RD99019>. Acesso em: 24 ago. 2011. doi: doi.org/10.1071/ RD99019.

PESCH, S.; BERGMANN, M. Structure of mammalian spermatozoa in respect to viability, fertility and cryopreservation. Micron, v.37, p.597-612, 2006. Disponível em: <http:// www.sciencedirect.com/science/article/pi i/ S0968432806000217>. Acesso em: 24 ago. 2011. doi:10.1016/ j.micron.2006.02.006

PURDY, P.H. A review on goat sperm cryopreservation. Small Ruminant Research, v.63, p.215-225, 2006. Disponível em: <http://www.sciencedirect.com/science/article/ pii/S0921448805000763>. Acesso em: 24 ago. 2011. doi:10.1016/j.smallrumres.2005.02.015.
ROTH, T.L. et al. Heterologous in vitro fertilization and sperm capacitation in an endangered African antelope, the Scimiltar-Horned Oryx (Oryx dammah). Biology of Reproduction, v.58, p.475-482, 1998. Disponível em: <http://www.biolreprod.org/content/58/2/475.full.pdf+html>. Acesso em: 24 ago. 2011. doi: 10.1095/?biolreprod58.2.475.

SARAIVA, K.L.A. et al. Chronic treatment with sildena?1 stimulates Leydig cell and testosterone secretion. International Journal of Experimental Pathology, v.90, p.454-462, 2009. Disponível em: <http://onlinelibrary.wiley.com/doi/10.1111/ iep.2009.90.issue-4/issuetoc>. Acesso em: 24 ago. 2011. doi: 10.1111/j.1365-2613.2009.00660.x

SIAS, B. et al. Cloning and seasonal secretion of the pancreatitc lipase-related protein 2 present in goat seminal plasma. Biochimica et Biophysica Acta (BBA) - Molecular and Cell Biology of Lipids, v.1686, p.169-180, 2005. Disponível em: <http://www.sciencedirect.com/science/article/ pii/S1388198104001635>. Acesso em: 24 ago. 2011. doi:10.1016/j.bbalip.2004.09.008

SINHA, M.P. et al. The effect of glutathione on motility, enzyme leakage and fertility of frozen goat semen. Animal Reproduction Science, v.41, p.237-43, 1996. Disponível em: <http://www.sciencedirect.com/science/article/pii/ 0378432095014500>. Acesso em: 24 ago. 2011. doi:10.1016/ 0378-4320(95)01450-0.

STATISTICAL ANALYSIS SYSTEM - SAS. SAS/STAT: user's guide. Version 6. 4.ed. Cary, 2001. V.2. (CD-Rom).

VERSTEGEN, J. et al. Computer assisted semen analyzers in andrology research and veterinary practice. Theriogenology, v.57, p.149-179, 2002. Disponível em: <http://www.sciencedirect.com/ science/article/pii/S0093691X01006641>. Acesso em: 24 ago. 2011. doi:10.1016/S0093-691X(01)00664-1.

VILLEMURE, $M$. et al. Isolation and characterization of gelatine-binding proteins from seminal plasma. Reproductive Biology and Endocrinology, v.1, p.39, 2003. Disponível em: 〈http://www.ncbi.nlm.nih.gov/pmc/articles/PMC155548>. Acesso em: 24 ago. 2011. doi: 10.1186/1477-7827-1-39. 